\title{
O perfil e a formação docente no curso de licenciatura em Geografia em uma universidade pública do Paraná
}

\author{
Pedro Henrique Carnevalli Fernandes ${ }^{1}$ \\ Roberta Negrão de Araújo² \\ Andreia Virginia da Silva ${ }^{3}$
}

\begin{abstract}
RESUMO
A presente pesquisa é resultado de um estudo exploratório acerca de um curso de Licenciatura em Geografia ofertado em uma universidade pública do Estado do Paraná. Objetivou compreender o perfil e a formação dos acadêmicos do referido curso. Foi desenvolvida pesquisa de revisão tendo referências que abordam a formação de professores. $\mathrm{Na}$ sequência, foi elaborado instrumento de coleta de dados, bem como a aplicação deste junto aos acadêmicos. Como objetivos específicos foram propostos: (1) debater a formação docente e a ciência geográfica; (2) entender o curso de Geografia investigado e o perfil dos acadêmicos; (3) compreender a formação em Geografia e as perspectivas acadêmicas dos futuros professores. Entre os principais resultados, os respondentes apontam a necessidade de uma formação acadêmica voltada, de fato, para a docência, pois consideraram os desafios em se estar em sala de aula e a ausência de uma formação que os prepare para isso.
\end{abstract}

PALAVRAS-CHAVE: Formação docente. Perfil docente. Ciência Geográfica. Ensino de Geografia.

\footnotetext{
${ }^{1}$ Doutor em Geografia pela Universidade Estadual de Maringá. Docente da Universidade Estadual do Norte do Paraná. Cornélio Procópio, Paraná, Brasil. https://orcid.org/0000-0001-7542-7912.pedrofernandes@uenp.edu.br.

${ }^{2}$ Doutora em Ensino pela Universidade Estadual de Londrina. Docente da Universidade Estadual do Norte do Paraná. Cornélio Procópio, Paraná, Brasil. https://orcid.org/0000-0002-3926-4746.robertanegrao@ uenp.edu.br.

${ }^{3}$ Especialista em Educação pela Universidade Estadual do Norte do Paraná. Cornélio Procópio, Paraná, Brasil. https://orcid.org/0000-0003-1226-4663. deia.virginia.silva@gmail.com.
} 
The profile and the teacher training in the degree course in Geography in a public university of Paraná

\begin{abstract}
The present research is the result of an exploratory study about a degree in Geography offered at a public university in the State of Paraná. It aimed to understand the profile and the training of the academics of said course. A review research was developed with references that address teacher training. A review research was developed with references that address teacher training. In the sequence, a data collection instrument was developed, as well as its application to academics. Specific objectives were proposed: (1) to discuss teacher education and geographic science; (2) understand the course of Geography investigated and the profile of the academics; (3) understand the training in Geography and the academic perspectives of future teachers. Among the main results, the respondents point out the need for an academic training that is, in fact, aimed at teaching, considering the challenges in being in the classroom and the absence of a training that prepares them for it.
\end{abstract}

KEYWORDS: Teacher training. Teacher profile. Geographical Science. Teaching Geography.

\title{
Introdução
}

A formação docente no Brasil passou por longa e árdua história. Esta tem, em sua trajetória, políticas públicas ligadas às reformas educacionais que deixaram resquícios atrelados aos contextos sociais, econômicos e políticos de cada período, em sua especificidade. Dessa forma, os problemas educacionais recaem na formação do sujeito que atuará nos mais variados cenários, dadas as condições peculiares de sua formação inicial e de como ela irá prepará-lo para a atuação. O fato é que a responsabilidade e o compromisso dos cursos de formação de professores estão cada dia maiores, pois, na sociedade atual, se apropriar dos conteúdos curriculares não é 
garantia de que o sujeito dará conta do processo de ensino e aprendizagem. Então, opta-se por um ensino crítico que prepare o sujeito para atuar na sociedade, em uma relação homem e meio dinâmica, reflexiva e transformadora.

Quanto ao ensino da Geografia, é prevista uma formação cujo sujeito compreenda que ele produz o espaço geográfico, assim como sua organização, por meio das suas relações sociais. Estas, por sua vez, se constroem historicamente, ou seja, como sujeito ativo, cabendo ao professor à busca contínua por condições para que de fato esse se insira na sociedade, não se alienando de suas responsabilidades.

Assim, escolheu-se como objeto deste estudo compreender o perfil e a formação dos acadêmicos de um curso de Licenciatura em Geografia de uma universidade pública do Estado do Paraná, bem como o impacto destas na formação de professores. Os objetivos específicos são: (1) debater a formação docente e a ciência geográfica; (2) descrever as características do curso de Geografia investigado e o perfil dos acadêmicos; (3) compreender a formação em Geografia e as perspectivas dos acadêmicos como futuros professores.

Os procedimentos metodológicos para a realização desta pesquisa foram: levantamento de referências que permitissem uma revisão bibliográfica do objeto de estudo conectado aos objetivos propostos; levantamento de informações no atual Projeto Pedagógico (PPC) do curso de Licenciatura em Geografia; aplicação de questionário nos acadêmicos do terceiro e do quarto ano do curso investigado,e, por fim, elaboração da redação final deste artigo.

O questionário foi composto por cinco questões que remetiam aos motivos que levaram a escolha pelo curso, as vertentes da ciência geográfica e a possível atuação dos acadêmicos como professores. A escolha do curso de Licenciatura em Geografia para análise e compreensão ocorreu, principalmente, por ele ser um dos cursos em atividade mais antigos do Estado do Paraná. 
O estudo foi organizado em três partes, além da introdução e das considerações finais. Na primeira abordou-se a formação docente, sobretudo acerca dos saberes profissionais. Na segunda parte, por meio de análise de documento, buscou-se compreender as diretrizes norteadoras do curso de Geografia e compreendê-las a partir de referências bibliográficas que orientaram o estudo exploratório proposto nesta pesquisa. Por fim, na última parte, é apresentada a análise dos questionários respondidos pelos acadêmicos envolvidos, que demonstra o que pensam sobre o curso e sobre a sua possível atuação na profissão docente.

\section{Formação Docente: versando sobre os saberes profissionais}

Pensar a ciência geográfica, assim como a formação docente, remete à reflexão das demandas da atual sociedade atrelada aos embates da contemporaneidade. Apesar disso, será que os cursos de licenciatura têm atingido essas reflexões e demandas? Esta parte da pesquisa tem como principal foco, então, transitar pela formação docente e pelos saberes profissionais, inclusive dentro da ciência geográfica.

Sobre isso, Pimenta (2002, p. 73) diz que "[...] repensar a formação inicial e contínua, a partir das práticas pedagógicas e docentes, tem se revelado como uma das demandas importantes dos anos 90". Essa necessidade segue até os dias atuais, uma vez que os estudos têm demonstrado que os cursos de licenciaturas desenvolvem um currículo com conteúdos e atividades distantes da realidade das escolas de educação básica (PIMENTA, 2002).

Considerando tal afirmação, esse distanciamento acaba não preparando o acadêmico para uma prática social que capte as contradições presentes no âmbito escolar, o que pouco contribui para a formação da identidade docente. A partir desse cenário, questiona-se: quais os saberes 
necessários para a formação profissional do sujeito, seja inicial ou continuada?

Tardif (2000, p. 5) questiona sobre "quais são os saberes profissionais dos professores, isto é, quais são os saberes (conhecimento, competência, habilidades, etc.) que utilizam efetivamente em seu trabalho diário para desenvolver suas tarefas e atingir seus objetivos?" Tal questão parece um desafio, tanto para o professor que está nas universidades, quanto para o professor da rede básica, que devem socializar o conhecimento científico com seus alunos.

A profissão docente, assim como as demais profissões, emerge de um dado momento histórico, dadas as necessidades emergentes, e, ao longo do tempo, umas deixam de existir e outras surgem de acordo com a demanda atual. Nesse cenário, a profissão "professor" se encontra na perspectiva das profissões que não chegam a desaparecer, mas que se transformam e adquirem novas características para responder as demandas sociais emergentes da atualidade (PIMENTA, 2002).

A construção da identidade é, portanto, construída, sendo algo decorrente de um processo e "[...], a partir da significação social da profissão; da revisão constante dos significados sociais da profissão; da revisão das tradições" (PIMENTA, 2002, p. 76). A formação da identidade docente se relaciona, portanto, com o seu cotidiano, seus valores, sua história de vida, e constrói de acordo com a forma como esse vivencia o mundo a sua volta.

Em face da formação da identidade profissional, os professores têm, de acordo com Pimenta (2002), três passos no processo de construção da identidade, sendo intitulados saberes da docência, a saber: (1) os saberes da experiência; (2) os saberes do conhecimento científico; e, (3) os saberes pedagógicos.

Os saberes da experiência são aqueles que os alunos detêm quando iniciam sua formação de docente, uma vez que esses já têm uma percepção sobre o que é ser professor. As experiências trazidas pelo indivíduo proporcionam um olhar sobre quais foram seus bons ou maus professores. 
Assim, o desafio posto para os cursos de formação inicial "[...] é o de colaborar no processo de passagem dos alunos de seu ver os professores como aluno ao seu ver-se como professor" (PIMENTA, 2002, p. 77).

O segundo saber docente posto por Pimenta (2002) é o do conhecimento e, para explicá-lo, a autora usa como exemplo alunos que cursam duas licenciaturas na Faculdade de Educação da Universidade de São Paulo (FEUSP). Destacam-se, aqui, os acadêmicos do curso investigado neste artigo; inseri-los no exemplo, supõe que, assim como os acadêmicos da FEUSP, esses compreendem que serão professores e que para tanto precisam deter conhecimentos acerca do espaço geográfico. Assim, para ensinar, precisam saber que sem o conhecimento específico não darão aulas com êxito.

O terceiro saber docente elucida os saberes pedagógicos. Esses dizem respeito ao saber ensinar e à sua epistemologia em relação ao saber fazer, em uma perspectiva de construção de práticas pedagógicas. Entretanto "[...] os práticos não o geram só com o saber da prática. As práticas pedagógicas se apresentam nas ciências da educação" (PIMENTA, 2002, p.82).

Partindo do cenário em que se encontram os saberes docentes, voltase para onde são aplicados: a escola, onde historicamente se trabalha com conhecimento está em constante mudança de cenários, os quais mudam sua perspectiva de ensino ora ou outro dependendo do contexto social que se instala no momento histórico. Para Tardif (2000), o fazer docente no seu cotidiano vai além dos conteúdos curriculares das grades curriculares das universidades. Não que esses não sejam suporte para produção de conhecimento, porém, os saberes profissionais dos docentes não se resumem a eles, mas, se integram a esses como parte do processo de formação (TARDIF, 2000).

Considerando que a didática trata do ensino, espera-se que ela prepare os futuros professores para que possam dar aulas. Assim, para ensinar, além de deter o conhecimento, faz-se necessário os saberes pedagógicos e didáticos. Logo, não é suficiente ter conhecimento se esse não 
for socializado com os estudantes de maneira que a aprendizagem seja efetivada. Da mesma forma, uma prática esvaziada de conhecimento científico é uma falácia ilusória.

A prática docente envolve situações de intencionalidade, as quais têm por objetivo o processo de ensino e aprendizagem e os enfrentamentos do cotidiano, se inserindo em parte da realidade escolar. Nesse cenário, "os saberes docentes podem colaborar com a prática. Sobretudo, se forem mobilizados a partir dos problemas que a prática coloca, entendendo, pois a dependência da teoria em relação à prática, pois esta lhe é interior" (PIMENTA, 2002, p. 83).

Os saberes profissionais são, portanto, resultado da ação dos estudos e experiências ao longo da vida docente, a qual se inicia na formação inicial e segue por toda a carreira docente, na qual o professor segue refletindo sobre a ação docente e fazendo dessa reflexão elemento para mudança e transformação de sua práxis de sala aula.Nesse processo de formação e construção da identidade, assim como dos saberes profissionais, Tardif (2000, p. 16) aponta que "o objeto do trabalho docente são seres humanos e, por conseguinte, os saberes dos professores carregam marcas do ser humano".

As particularidades individuais do professor e do aluno corroboram a formação dos saberes profissionais, logo, conhecer o aluno é para o professor uma tarefa pouco desenvolvida e, eventualmente, confundida com sua própria história escolar (TARDIF, 2000). Então, a "aquisição da sensibilidade relativa às diferenças entre alunos constitui uma das principais características do trabalho docente" (TARDIF, 2000, p. 17).

A formação docente implica uma série de especificidades que não se separam da particularidade de cada um, tão pouco da sua formação inicial. "Produzir a vida do professor implica em valorizar, como conteúdos de sua formação, seu trabalho crítico-reflexivo sobre as práticas que realiza e sobre as suas experiências compartilhadas" (PIMENTA, 2002, p. 85). 
Os alunos passam um certo número de anos a assistir aulas baseadas em disciplinas e constituídas de conhecimentos proposicionais. Em seguida, ou durante essas aulas, eles vão estagiar para "aplicarem" esses conhecimentos. Enfim quando a formação termina, eles começam a trabalhar sozinhos, aprendendo seu ofício na prática e constatando, na maioria das vezes, que esses conhecimentos proposicionais não se aplicam na ação cotidiana (WIDEEN, 1998, apud TARDIF, 2000, p. 18).

Considerando os estudos de Tardif (2000), há pontos com maiores limitações na formação profissional, demonstrando que, assim como pontuou Pimenta (2002), estes se apresentam na formação inicial. Pimenta (2002, p. 87) ainda contribui: “[...] a formação de professores na tendência reflexiva se configura como uma política de valorização do desenvolvimento pessoalprofissional dos professores e das instituições escolares". A reflexão acerca da própria prática não é uma tarefa fácil, uma vez que se deve iniciar essa análise no cerne das instituições de formação, iniciando-a pelos próprios professores que estão formando novos profissionais, uma vez que esses fazem parte do processo de formação profissional no sentido temporal e irão construir a identidade do professor em formação, assim como sua própria.

E se tratando da formação do professor de Geografia esse deve formar-se para atuar em sociedade com bases teóricas que oportunizem condições de exercer a profissão docente, sendo necessária apropriação da ciência geográfica pelo viés do espaço geográfico e da construção social desse espaço.

\section{O curso de licenciatura em Geografia: uma análise sobre a formação para o trabalho docente}

A Geografia no Brasil desenvolveu-se à luz de autores como Humboldt, Ritter e Vidal de La Blace, sendo que a Geografia como disciplina 
escolar perpassou a escola de primeiras letras, tornando-se matéria específica escolar em 1831. (MELO; VLACH; SAMPAIO, s/d).

Considerada um saber essencial na formação dos bacharéis, futuros intelectuais e administradores do país, a Geografia ganha o status de matéria quando passa a ser estudada em "aulas" preparatórias para a admissão nas faculdades de Direito. Em 1837, aparece pela primeira vez como componente do "Programa" de conteúdos do Colégio Pedro II (MELO; VLACH; SAMPAIO, s/d, p. 2.685).

A sistematização da Geografia enquanto disciplina se deu de fato nos séculos XIX e XX.

É importante lembrar que o aparecimento do saber institucionalizado da Geografia, data de pouco mais que um século que a época de seu nascimento, isto é, final do século XIX e começo do século $\mathrm{XX}$, se vincula à vertente oposta àquela da escalada do capitalismo que corresponde á sua fase progressiva, o que vale dizer que sua origem é ideológica, no qual o saber só tem existência institucional enquanto instrumento de dominação de uma classe (LEONEL, 1985, p. 10 apud MORMUL; ROCHA, 2013, p. 66).

As discussões acerca da institucionalização da Geografia perpassaram por períodos que atenderam desde guerras, lutas classistas até sua organização como ciência geográfica que se utiliza, atualmente, nas academias, cuja orientação de sua trajetória como disciplina foi norteada pelos pressupostos da Geografia Clássica e da Geografia Moderna.

Os cursos superiores de Geografia começaram a partir da década de 1930, com as chamadas faculdades de "História e Geografia", sendo que os licenciados em Geografia foram os primeiros a participarem de campos regionais e a produzirem monografias acerca do território nacional. Assim, possuíam alunos e professores preocupados em “desenvolverem a Ciência 
Geográfica e torná-la cada vez mais independente, com o seu próprio objeto de estudo e, ao mesmo tempo, mais "útil" à sociedade" (MELO; VLACH; SAMPAIO, s/d, p. 2.687).

A institucionalização de cursos de Geografia com objetivos voltados à sociedade influenciou na aprovação, pelo Conselho Estadual de Educação, em 1966, do curso de Licenciatura em Geografia, estudado neste artigo, em uma Instituição Pública do Estado do Paraná, O Projeto Pedagógico do Curso (PPC) de Licenciatura em Geografia em vigor evidencia a busca em compreender a dinâmica do espaço geográfico, o qual era comum ser visto de forma fragmentada, considerando, sobretudo, que as relações sociais e o perfil dos alunos, assim como de escolas correspondem a outras realidades.

As transformações ocorridas na sociedade são parte do processo histórico decorrentes da evolução das ações do homem no espaço. De acordo com o Currículo Básico da Escola Pública do Paraná, a Geografia "trata, portanto, da produção e da organização do espaço geográfico, a partir das relações sociais de produção, historicamente determinados" (PARANÁ, 1992, p. 99).

Acompanhando a mudança no cenário, o curso de Licenciatura em Geografia investigado buscou, em suas diretrizes curriculares, priorizar as disciplinas que acompanham a evolução da ciência geográfica, introduzindo e aprofundando suas metodologias e tecnologias de apresentação do espaço geográfico. De acordo com o PPC atual, apresenta o desafio não apenas de formar o geógrafo-pesquisador (técnico e planejador), mas, o geógrafoprofessor do ensino fundamental, médio e superior. Com formação polivalente e holística as particularidades do curso estão voltadas ao ensino, dadas às necessidades de atender ao mercado de trabalho da região.

Considerando que a Geografia visa compreender o espaço e suas transformações, o curso objetiva uma formação holística do profissional licenciado, e que essa seja sólida, ética, moral e comprometida com a evolução e transformação da sociedade brasileira. 
As competências, habilidades e perfil do profissional licenciado para atuação profissional seguem uma série de especificidades atreladas, sobretudo, a ciência geográfica e sua atuação sobre ela, sendo que sobre o perfil do profissional:

O profissional (licenciado em Geografia) deverá ser capaz de: Interpretar criticamente a organização do espaço produzido pela relação dos homens entre si e com a natureza, nas suas diferentes configurações territoriais e ambientais; Analisar as relações especializadas da estrutura econômica, social e política das sociedades contemporâneas; [...] Interpretar e analisar as questões relacionadas com o Ensino da Geografia, diante da Política Educacional Brasileira no momento atual; Refletir a questão pedagógica dentro do Ensino da Geografia, ou seja refletir o Ensino da Geografia não apenas com uma reflexão epistemológica mas também a sua relação com as questões pedagógicas; Compreender as categorias fundamentais de análise geográfica para saber o papel da Geografia no Ensino e construir um olhar geográfico da realidade e procurar entender o mundo atual e se instrumentalizar para viver como cidadão (PARANÁ, 2011, p. 12).

O PPC apresenta habilidades e competências do profissional visando, sobretudo, priorizar a visão holística da Geografia em suas especificidades. Objetiva, então, preparar esse profissional para o campo de atuação, seja ele geógrafo-pesquisador e/ou geógrafo-professor, ressaltando que a diretriz do curso prioriza a formação do professor, porém, amplia-se para uma formação técnica seguindo a legislação atual (PARANÁ, 2011).

Existe uma preocupação, portanto, do curso em formar profissionais que deem conta dessa nova demanda social. É uma preocupação válida e fundamental para o contexto atual.

As demandas dessa nova sociedade são resultantes das transformações dadas pelas "relações de produção e de trabalho, de que o homem participa com a natureza e com outros homens para satisfazer suas 
necessidades" (ABBAGNADO, 1998, p. 762 apud MARTINS, 2007, p. 29). Tal campo de transformação é instrumento de trabalho da Geografia, assim como houve uma renovação do pensamento geográfico, evidencia-se uma perspectiva de trabalho para superação de condições sociais postas pela sociedade capitalista.

É a via revolucionária da renovação do pensamento geográfico, que agrupa aqueles autores imbuídos de uma perspectiva transformadora, que negam a ordem estabelecida, que veem seu trabalho como instrumento de denúncia e como arma de combate; enfim, que propõem a Geografia como mais um elemento na superação da ordem capitalista (MORAES, 1999, p. 115 apud SANTOS, FILHO, 2010, p. 27).

A transformação social ocorre, sobretudo, na forma de tomada de consciência das mudanças ocorridas e do papel do sujeito, nesse cenário, o profissional docente, sendo que, a educação pode ser instrumento para formação diferenciada.

A árdua tarefa de ser um profissional na área da educação implica em um processo que envolve intencionalidade de transformação, cujo em seu trabalho, enquanto "trabalhador e junto de outros homens, modifica intencionalmente as condições externas, modificando-se a si mesmo" (MARTINS, 2009, p. 148).

O professor é resultado do processo de construção histórica, assim como seus alunos, não sendo possível separar o eu profissional do eu pessoal: A maneira como cada um de nós ensina está diretamente dependente daquilo que somos como pessoa quando exercemos o ensino [...] Eis-nos de novo face à pessoa e o profissional, ao ser e ao ensinar. Aqui estamos. Nós e a profissão, as quais cruzam a nossa maneira de ser, com a nossa maneira de ensinar e desvendam na nossa maneira de ensinar a nossa maneira de ser. É impossível separar o eu profissional do eu pessoal (NÓVOA, 1992 apud MARTINS, 2007, p. 11). 
Considerando a produção social do sujeito, as diretrizes curriculares da Educação Básica de Geografia (PARANÁ, 2008, p. 14) apontam que "um sujeito é fruto de seu tempo histórico, das relações sociais em que está inserido, mas é, também, um ser singular, que atua no mundo a partir do modo como o compreende e como dele lhe é possível participar". Nessa mesma perspectiva, encontra-se o professor, enquanto sujeito, e nesse mundo se insere a escola.

A clareza no papel do professor se encontra na intencionalidade do processo educativo, bem como na tomada de consciência de que esse processo se dá na medida de sua formação enquanto sujeito, enquanto acadêmico e enquanto futuro professor, como resultado de construções sociais ao longo de sua vida e de suas atuações no espaço em que se insere.

Atualmente, o curso investigado se ancora com proposta pedagógica implantada em 2012, com 3.100 horas, em regime seriado, com a oferta de 40 vagas por ano em período noturno. Com modalidade presencial, o acadêmico tem como período de integração o mínimo de quatro anos e o máximo de sete anos (PARANÁ, 2011).

\section{O curso de Geografia na percepção dos acadêmicos envolvidos}

Com o objetivo de evidenciar a percepção dos acadêmicos no que tange à formação para a docência, elaborou-se um instrumento de coleta de dados: o questionário. Este foi aplicado junto aos acadêmicos que estão cursando o terceiro e quarto ano do curso investigado. A escolha por essas turmas devese ao fato de serem as que possuem o contato direto com a sala de aula, por meio dos estágios obrigatórios.

Foi realizada pesquisa exploratória, cujo objetivo, segundo Gil (2008, p. 41), é "[...] proporcionar maior familiaridade com o problema, com vistas a torna-lo mais explícito ou construir hipóteses”, optando-se por questionário 
como instrumento de investigação, contendo perguntas abertas e fechadas, sendo esse analisados qualitativamente.

$\mathrm{O}$ instrumento foi composto por cinco questões que remetem aos motivos que levaram a escolha pelo curso de Licenciatura em Geografia, as vertentes da ciência geográfica e a possível atuação dos acadêmicos como professores.

Os acadêmicos do terceiro e quarto ano do curso somam 45 alunos matriculados, sendo que 36 deles aceitaram participar da pesquisa, gerando uma participação de $80 \%$ dos alunos matriculados. Desse universo, 23 cursam o terceiro ano (79,3\% dos alunos matriculados) e 13 o quarto ano (81,3\% dos alunos matriculados). Em uma primeira avaliação do perfil dos acadêmicos, evidenciou-se que a maioria deles reside fora da cidade onde o curso é ofertado.

A turma do terceiro ano tem, na sua maioria, idade entre 19 e 30 anos, sendo que o mais jovem tem 19 anos e o mais velho 46 anos. No quarto ano, o panorama não se altera, predominam acadêmicos, na maioria, na faixa dos 20 aos 30 anos, no qual o mais jovem tem 21 anos e o mais velho 48 anos.

Para analisar as respostas, os acadêmicos foram codificados de "A01" a “A36", acrescentado de "/3", para os acadêmicos do terceiro ano, e, “/4", para os acadêmicos do quarto ano. Então, por exemplo, o respondente "A03/3" corresponde ao terceiro acadêmico do terceiro ano que respondeu o questionário; enquanto que o respondente “A33/4" corresponde ao trigésimo terceiro respondente, este sendo do quarto ano.

A primeira questão refere-se aos motivos que levaram o acadêmico a optar pelo curso de Licenciatura em Geografia. Os acadêmicos respondentes escolheram o curso, em sua maioria, porque gostam da Geografia. Em seguida, apareceram como motivações: a proximidade com a casa; a vontade de ser professor; as questões profissionais; e, ainda, por ser o curso em uma universidade pública. A motivação pela escolha do curso foi semeada, para alguns, durante o ensino médio, sendo que para alguns de forma positiva e 
para outros de forma negativa, sendo ele atrelado à mudança, como descreve um respondente:

Era uma disciplina que gostava no Ensino Médio, porém não tinha bons professores e isso me motivou a fazer o curso, para não ser igual a eles $\left(A 31 / 4^{\circ}\right)$.

Sobre a influência da Geografia escolar como motivação, pode-se dizer que esses decorrem, sobretudo, devido à influência e à presença da Geografia no cotidiano dos alunos.

Uma vez que os temas de geografia acompanham e fazem parte do cotidiano das pessoas, inscrevendo-se nas suas condições de existência, tal fato parece justificar sua popularidade. [...] Nós percebemos a geografia e aprendemos por força do nosso próprio cotidiano (MOREIRA, 2005, p. 56 apud SANTOS; FILHO, 2010, p. 19).

Considerando o cotidiano da Geografia e atrelando, possivelmente, à prática de professores em sala de aula, apresentam-se alguns motivos descritos pelos acadêmicos respondentes:

Influência de professores que tive no decorrer do ens. Fundamental II e médio $\left(A 15 / 3^{\circ}\right)$.

Professores do Ensino Médio e sua dedicação pela disciplina, fizeram com que estivesse escolhendo o curso $\left(A 8 / 3^{\circ}\right)$.

O que me motivou a escolher a Licenciatura em Geografia foi no magistério onde tive uma professora que acabou transmitido sua paixão pela matéria, e assim fazendo com que os alunos gostassem de Geografia $\left(A 20 / 3^{\circ}\right)$.

Outros acadêmicos associaram a escolha pelo curso à oportunidade de ser professor. Essa escolha aparece mesmo com um panorama em que a profissão docente se encontra desvalorizada por alguns segmentos da 
sociedade, por alguns grupos políticos e até por parcela da mídia. Os índices estatísticos, de acordo com Plano Emergencial para Enfrentar a Carência de Professores no Ensino Médio: Chamada Nacional, de abril de 2005, apontam que apenas 26\% dos professores de Geografia do Ensino Médio são formados e que a evasão nos cursos de Licenciatura em Geografia chega a 47\% (RUIZ; RAMOS; HINGEL, s/d).

Tal motivação pode, futuramente, reduzir essa estatística, se atrelada a uma formação de qualidade e que oportunize ao acadêmico ter interesse pela profissão docente.

O que me motivou foi a oportunidade em ingressar na carreira do professor pela circunstância em que está a Educação no Brasil $\left(A 25 / 4^{\circ}\right)$.

Continuar na área da educação, em um curso gratuito e próximo da minha cidade, como já tenho o magistério não queria sair da área e Geografia porque tinha facilidade na compreensão da matéria $\left(A 24 / 4^{\circ}\right)$.

A segunda questão fez menção às três vertentes do curso: o Ensino de Geografia, a Geografia Física e a Geografia Humana. Foi perguntado se os acadêmicos respondentes percebem a predominância de uma vertente em detrimento da outra e, em caso positivo de respostas, qual vertente e como justifica essa resposta.

De acordo com Silva (s/d, p. 41), "[...] a dicotomia entre Geografia Humana e Geografia Física enfraquece a ciência geográfica, pois, ao renegar uma delas, o geógrafo restringe o seu campo de trabalho." Sendo assim, em um curso de formação de professores espera-se que essa dicotomia seja superada por uma Geografia com visão holística e atrelada ao Ensino da Geografia.

No total, $58,3 \%$ dos acadêmicos respondentes disseram que "não" há predominância de uma vertente em detrimento da outra no curso de Licenciatura de Geografia pesquisado. Apesar disso, 33,3\% dos acadêmicos 
respondentes pontuaram que "sim", existe predominância de uma vertente em detrimento da outra no curso. O restante, 8,4\%, não respondeu a questão.

Nos acadêmicos que responderam que não existe o domínio de uma vertente sobre a outra, não houve menção ao Ensino de Geografia, uma vez que apontaram a Geografia Física e a Geografia Humana. Assim, ocorreu uma divisão de opiniões e pontos de vistas que ora consideram as três vertentes, ora não, uma vez que dentre os que mencionam a diferença, destaca-se que alguns não incluem o ensino.

Os professores mostram os dois lados da moeda e assim cada aluno defini qual ramo seguir $\left(A 2 / 3^{\circ}\right)$.

As três são trabalhadas no curso de Geografia $\left(A 31 / 4^{\circ}\right)$.

Penso que as duas vertentes tanto a humana quanto a física é bem mais trabalhada no Ensino de Geografia $\left(A 20 / 3^{\circ}\right)$.

Entre os respondentes que reconheceram a existência de uma vertente predominante sobre as outras, nenhum citou a vertente Ensino de Geografia, o que causou uma relativa preocupação, sobretudo por se tratar de um curso de licenciatura. Entre as vertentes da Geografia Humana e da Geografia Física, a Geografia Humana apareceu com maior predominância.

A maior parte dos professores da área Física e Educação possuem outros projetos e acabam não se dedicando integralmente as aulas $\left(A 33 / 4^{\circ}\right)$.

Teria que ser mais distribuído puxando mais para o ensino, o foco das matérias $\left(A 24 / 4^{\circ}\right)$.

Sou contra essa divisão ser tratada tão a fundo. No curso nota-se que dão predominância à vertente humana, sendo que todas deveriam ser trabalhadas na mesma proporção, com o mesmo comprometimento $\left(A 15 / 3^{\circ}\right)$. 
Visto que existe uma disparidade entre as opiniões, observando que existe uma preocupação dos acadêmicos em se ter acesso às três vertentes, é importante fundamentar cientificamente que esse fenômeno não ocorre de forma isolada, ou seja, atinge praticamente todos os cursos de Licenciatura em Geografia.

[...] perplexos diante da disparidade de disciplinas que compõem a formação geográfica universitária, aliada a ideologia expressa por cada um dos seus mestres em relação à geografia que praticam, levam-nos a uma paradoxal busca de unidade do pensamento geográfico (MENDONÇA, 1998, p.25 apud SILVA, s/d, p. 43).

Nas questões que tratavam da parte profissional (terceira e quarta questões), sobre a escolha em atuar ou não como professor e se o curso promove uma formação adequada à docência e uma possível atuação no mercado de trabalho, a maioria pontuou que quer ser professor. Já sobre a preparação para o mercado de trabalho, houve controvérsias acerca do curso.

Dos que assinalaram que o curso prepara parcialmente para o mercado de trabalho destacam-se as seguintes respostas:

Precisa ter mais conceitos voltados para a docência $\left(A 26 / 4^{\circ}\right)$.

Penso que ainda falta algumas matérias na grade do curso e mais trabalhos voltados a nossa atual sociedade no mundo escolar $\left(A 13 / 3^{\circ}\right)$.

A visão que tenho é a de que o curso quer alunos que se dediquem exclusivamente para a faculdade. Cobram muito artigo, seminários e acabam deixando o conteúdo a desejar. Nos alunos trabalhadores aprendemos muito pouco com essa metodologia $\left(A 33 / 4^{\circ}\right)$.

Se o curso é voltado para a licenciatura poderia focar em formação para tal. Não é o que acontece, sinto que estou saindo do curso sem uma formação ampla $\left(A 35 / 4^{\circ}\right)$. 
Compreende-se que o curso de Licenciatura em Geografia deve ser focado nos saberes profissionais. De acordo com Lopes (2010, p. 14), “[...] a prática profissional docente, deste modo, não é apenas lugar de "aplicação" de saberes produzidos no lugar competente - a academia - e sim espaço privilegiado da produção de saberes profissionais específicos".

Dessa forma, para os que responderam que sim, que o curso prepara para o mercado de trabalho, seguem as respostas que se destacaram dialogando com o que o autor pontua como sendo espaço privilegiado de produção dos saberes.

Sim, pois vivenciamos vários métodos que podem ser aplicados em sala de aula $\left(A 20 / 3^{\circ}\right)$.

Promove formação adequada tanto para docência ou outras áreas $\left(A 15 / 3^{\circ}\right)$.

Verifico que aquilo que aprendo em sala de aula tem me ajudado nos estágios, portanto o curso tem me dado a formação adequada $\left(A 31 / 4^{\circ}\right)$.

Acho que o curso é bom, porque o que faz o curso funcionar é o esforço do aluno $\left(A 25 / 4^{\circ}\right)$.

Entre os acadêmicos respondentes que se mencionaram que o curso não prepara adequadamente para a atuação docente, pode-se observar que a maioria criticou algumas práticas docentes, que segundo eles não formam para a docência. As respostas destacadas que sinalizam isso foram:

Nem todos os professores promovem o ensino de forma a ensinar os conteúdos, a maioria deles só da resenha, resumo e seminário $\left(A 24 / 4^{\circ}\right)$.

Porque os conteúdos da geografia são bem explorados, porém várias obrigações do curso (trabalhos) fazem com que nós alunas nos concentremos em aspectos que não nos dá tanto aporte como licenciados $\left(A 32 / 4^{\circ}\right)$. 
$\mathrm{Na}$ quinta e última questão, os respondentes foram instigados a fazer uma breve avalição do curso, atrelado à formação inicial de professores e a possível atuação desses no mundo do trabalho, sobretudo, na Educação Básica de Ensino.

De acordo com Cacete (2015, p. 5), “[...] os cursos de licenciatura seguem este paradigma instrumental, ou seja, o professor deve ser instrumentalizado, instruído, deve saber técnicas e métodos".

Certamente, faz-se necessário que o professor aprenda tudo isso, entretanto, as situações vivenciadas em sala de aula não seguem um manual técnico de possiblidades de atuação sobre essas. Sendo assim, a situação de sala de aula requer uma situação específica, contextualizada, "e nem sempre aquilo que se aprende na teoria se configura como passível de aplicabilidade. Esse discernimento é fundamental à qualidade de nossos cursos de formação de professores" (CACETE, 2015, p. 5).

Estar preparado para o ingresso na carreira docente exige muito mais do acadêmico do que métodos e técnicas esvaziadas de conteúdo, esse deve compreender a sociedade como um todo, deve se apropriar do objeto da Geografia e fazer uso dele em seu cotidiano, não apenas para aplicar seu conteúdo, mas nos desafios de sala de aula.

Sobre a atuação do professor e o perfil desse profissional, o curso propõe:

Refletir a questão pedagógica dentro do Ensino da Geografia, ou seja refletir o Ensino da Geografia não apenas com uma reflexão epistemológica mas também a sua relação com as questões pedagógicas; Compreender as categorias fundamentais de análise geográfica para saber o papel da Geografia no Ensino e construir um olhar geográfico da realidade e procurar entender o mundo atual e se instrumentalizar para viver como cidadão; Reconhecer as tarefas que a escola e a Geografia tem atualmente na formação dos indivíduos capacitando-os a viverem numa sociedade informatizada e globalizada, pensando cientificamente e 
assumindo atitudes éticas que valorizem os direitos humanos fundamentais (PARANÁ, 2011, p.13).

Considerando o posicionamento dos alunos acerca de suas respostas e ainda atrelando aos objetivos contidos no PPC do curso voltados à formação de professores, as respostas dos acadêmicos respondentes demostraram, na sua maioria, que o curso pode ser melhorado em aspectos voltados à mudança de grade curricular privilegiando a licenciatura e uma formação centrada no ensino, com visão holística como propõe o documento.

O curso é excelente onde $90 \%$ dos professores são qualificados para ensinar, porém 10\% apresentam metodologias tradicionais $\left(A 17 / 3^{\circ}\right)$.

O curso tem muito a melhorar. Os professores são muito bons, mas a estrutura da universidade é precária e também seria interessante a interdisciplinaridade com outros cursos $\left(A 10 / 3^{\circ}\right)$.

$O$ curso é bom, mas peca numa melhor preparação $e$ instrumentalização para formar professor apto $\left(A 11 / 3^{\circ}\right)$.

Prefiro não avaliar o curso, pois entrei motivado para ser professora e estou saindo sem interesse pela profissão (A34/4).

O curso é bom, trabalha e explora os conteúdos e conceitos necessários para ser um docente, mas, poderia dar mais ênfase na formação dos alunos, no sentido de como vão se sair na sala de aula $\left(A 32 / 4^{\circ}\right)$.

O curso não é muito predominante para o ensino na Educação Básica $\left(A 27 / 4^{\circ}\right)$.

Bom curso $\left(A 19 / 3^{\circ}\right)$.

$O$ curso proporcionou muitos conhecimentos, mas não foi muito voltado pra a educação básica $\left(A 30 / 4^{\circ}\right)$.

O curso é bom, porém, tem muito a melhorar especialmente o que relaciona a tratar da verdadeira realidade da Educação Básica e não basear-se em visões românticas e ilusórias $\left(A 36 / 4^{\circ}\right)$.

Traz uma boa formação $\left(A 26 / 4^{\circ}\right)$. 
A percepção dos acadêmicos respondentes evidencia que o curso investigado pode ser aperfeiçoado no que tange à preparação para a docência. Na realidade, as mudanças na sociedade sempre levam a se pensar em alterações nas situações existentes, assim, é preciso avaliar e repensar as práticas constantemente.

\section{Conclusão}

Traçar o perfil de formação docente atrelado ao curso de Licenciatura em Geografia é algo que exigiu, antes de qualquer outra perspectiva, o bom senso e o discernimento de se pesquisar tal cenário. Nesse contexto, foi considerado não apenas a instituição, em sua especificidade do curso de Licenciatura em Geografia, mas, visto de um panorama que engloba além do seu contexto histórico enquanto curso de formação de professores, mas todo o contexto histórico da Geografia e de sua construção enquanto ciência.

O curso pode ser considerado um curso dos mais antigos em funcionamento no Estado do Paraná e, ao mesmo tempo, pode ser considerado um curso jovem por contar com muitos docentes novos; assim, é um curso ainda em desenvolvimento de seus objetivos, sobretudo, voltado à formação de professores. Observa-se que, atualmente, ele está construindo sua identidade, seu perfil enquanto curso acadêmico.

Foi evidenciado na análise do PPC em vigor do curso estudado, que esse tem objetivos voltados para a docência, entretanto, expande seu leque para o geógrafo-pesquisador, dado as demandas da sociedade, o que é compreendido como sendo outra possibilidade de atuação profissional. Isso é importante, porém, não se pode deixar de assinalar que se trata, sobretudo, de um curso de licenciatura, com objetivos voltados a essa formação especificamente. 
Evidencia-se, então, um panorama com algumas disparidades entre o proposto no documento analisado e a realidade posta pelos acadêmicos respondentes, que reconhecem a qualidade do curso, porém, apontam a necessidade de uma formação acadêmica voltada de fato para a docência, pois alguns respondentes consideraram em suas respostas os desafios em se estar em sala de aula e a ausência de uma formação que os prepare para isso.

O perfil dos profissionais almejado para atuação em sala de aula deve, assim como sugerido pelos acadêmicos respondentes, ir de encontro com a realidade da educação brasileira, sendo que o primeiro passo foi dado, pois se verifica uma formação na sua maioria crítica.

O questionário aplicado possibilitou uma breve análise acerca do que os acadêmicos respondentes esperam do curso, assim como características de quem o procura, traçando um perfil dos sujeitos. Estes buscam, sobretudo, por formação profissional e mesmo quando atrelam a comodidade por estarem próximos de suas casas, ou por se tratar de uma universidade pública, ainda sim, em sua maioria, tem foco na docência, e como parte de sua formação crítica apontam lacunas a serem preenchidas e superadas no curso, que deve, sobretudo, focar-se no seu maior objetivo que é "possibilitar uma formação holística do profissional licenciado em Geografia” (PARANÁ, 2011, p. 11).

Nas condições sociais atuais, não é algo fácil concluir uma graduação em licenciatura, sobretudo pela desvalorização da carreira docente associada ao sucateamento das universidades públicas, que acabam influenciando no resultado final do processo de formação. Entretanto, é preciso superar tais mazelas, concentrar os esforços no possível, no material humano, nos futuros professores, ofertando as condições mínimas de atuação. Nessa perspectiva, o resultado final implicará, diretamente, na forma como esses irão conduzir o Ensino de Geografia, fazendo uso do instrumento da Geografia e de toda a sua amplitude para garantirem um ensino de 
qualidade, com sujeitos que atuem na sociedade, como agentes transformadores do espaço em que vivem.

\section{Referências}

CACETE, N. H. FORMAÇÃO DO PROFESSOR DE GEOGRAFIA: SOBRE PRÁTICAS DE ENSINO E ESTÁGIO SUPERVISIONADO. Revista da Casa da Geografia de Sobral (RCGS), v. 17, n. 2, p. 3-11, 31 jul. 2015. Disponível em: http://rcgs.uvanet.br/index.php/RCGS/article/view/240/0. Acesso em: out. 2017.

GIL, A. C.. Métodos e Técnicas de pesquisa social. 6 ed. São Paulo. Editora Atlas, 2008.

LOPES, C. S. O professor de Geografia e os Saberes Profissionais: o processo formativo e o desenvolvimento da profissionalidade. São Paulo, 2010. Disponível em:

http://www.educadores.diaadia.pr.gov.br/arquivos/File/2010/artigos_teses/2010/Geo grafia/teses/tese_saberes_geo.pdf. Acesso em outubro de 2017

MARTINS, L. M. A formação social da personalidade do professor: um enfoque vigotskiano. Campinas, SP: Autores Associados, 2007.

MARTINS, Lígia Márcia. A Personalidade do Professor e a Atividade Educativa. In: Escola de Vigotski: contribuições para Psicologia e Educação. Maringá: Eduem, 2009.

MELO, A. de Á.; VLACH, V. R. F.; SAMPAIO, A. C. F. História da Geografia Escolar Brasileira: Continuando a discussão. Disponível em: http://www2.faced.ufu.br/colubhe06/anais/arquivos/239AdrianyMelo_VaniaRubia.p df. Acesso em: set. 2017.

MORMUL, N. M.; ROCHA, M. M.. Breves considerações acerca do conhecimento geográfico: elementos para análise. Geografia Ensino \& Pesquisa, vol. 17, n. 3, set.l dez. 2013.

PARANÁ/ Instituição investigada. Projeto Pedagógico de Curso. Paraná. 2011.

PARANÁ, Diretrizes Curriculares da educação Básica. Geografia. Secretaria de Estado de Educação do Paraná. 2008.

PARANÁ, Currículo Básico para Escola Pública do Paraná. Curitiba, 1992.

PIMENTA, S.G (org.). Saberes pedagógicos e atividade docente. 2. ed. São Paulo: Cortez, 2002.

RUIZ, A. I.; RAMOS, M. N.; HINGEL, M. Escassez de professores no ensino médio: soluções emergenciais e estruturais. Disponível em: 
https://www.senado.gov.br/comissoes/CE/AP/PDE/AP_03_CNE.pdf. Acesso em: out. 2017.

SANTOS, L. P. dos; FILHO, F. D. A. O estudo do lugar no ensino de Geografia: os espaços cotidianos na Geografia escolar. Rio Claro, SP, 2010. Disponível em: https://repositorio.unesp.br/bitstream/handle/11449/95559/santos_lp_me_rcla.pdf?s equence=1\&isAllowed=y. Acesso em: ago. 2017.

SILVA, S. H. P. Geografia Física e Geografia Humana: uma dicotomia a ser superada? Outros Tempos, www.outrostempos.uema.br, ISSN 1808-8031, volume 04. Disponível em: http://www.outrostempos.uema.br/Volume04/vol04art05.pdf. Acesso em outubro de 2017.

TARDIF, M. Saberes profissionais dos professores e o conhecimento universitário. Elementos para uma epistemologia da prática profissional dos professores e suas consequências em relação à formação para o magistério. Revista de educação. Jan/ $\mathrm{fev} / \mathrm{mar} / \mathrm{abr}, \mathrm{n} .13,2000$. 